\title{
EFEITOS DAS MUDANÇAS CLIMÁTICAS SOBRE A ALIMENTAÇÃO E A FISIOLOGIA DE ANFÍPODES HERBÍVOROS: DIFERENTES ESPÉCIES SIMPÁTRICAS ESTÃO SUJEITAS AOS MESMOS EFEITOS?
}

\author{
Ferreira, A.P. ${ }^{1,}$; Machado, G.B.O.. ${ }^{1}$ Pardo, J.C.F. ${ }^{2}$; Costa, T.M. $^{2}$ \& Leite, F.P.P. ${ }^{1}$ \\ ${ }^{1}$ Universidade Estadual de Campinas (Unicamp), Laboratório de Interações entre Comunidades Marinhas. \\ ${ }^{2}$ Universidade Estadual de São Paulo (Unesp), Laboratório de Ecologia e Comportamento Animal. \\ *Autor correspondente: anapaulaferre@gmail.com
}

Ecossistemas costeiros são ambientes altamente dinâmicos e sujeitos a diferentes impactos ambientais, como os decorrentes das mudanças do clima. Entre as alterações previstas, o aquecimento e a acidificação da água do mar podem afetar diretamente as macroalgas marinhas e os organismos que vivem associados a elas, pois atuam diretamente sobre os processos biológicos desses organismos, como a fisiologia e o comportamento. O objetivo desse trabalho foi avaliar como o aquecimento e a acidificação oceânica afetam a alimentação e a fisiologia dos anfípodes Hyale niger (Haswell, 1879) e Cymadusa filosa Savigni 1816, espécies de herbívoros que co-ocorrem em associação com a alga parda Sargassum filipendula. Para isso, fizemos três experimentos separadamente, avaliando o consumo de algas e as taxas de respiração e excreção de amônia dos herbívoros quando expostos a quatro tratamentos distintos: temperatura e $\mathrm{pH}$ ambiente (controle), aumento de temperatura $\left(+3^{\circ} \mathrm{C}\right)$, redução de $\mathrm{pH}(-0,03)$ e um tratamento combinando ambas alterações ambientais $\left(+3^{\circ} \mathrm{C}\right.$ e $\left.-0,03 \mathrm{pH}\right)$. Para $H$. niger, não foi observado alterações nas taxas alimentares, respiratórias e nem na excreção de amônia nos tratamentos com aquecimento e acidificação. Em contraste, observamos um aumento na excreção de amônia e uma diminuição da taxa respiratória de C. filosa no tratamento com aumento de temperatura $\left(+3^{\circ} \mathrm{C}\right)$. Além disso, para esse anfípode, houve uma redução do consumo alimentar em todos os tratamentos em relação ao controle. A temperatura atua diretamente sobre a homeostase dos organismos, pois catalisa as reações metabólicas. Por isso, o aumento da temperatura pode alterar os parâmetros fisiológicos, como observamos nesse experimento para a espécie C. filosa. Já o pH, apesar de apresentar efeito sobre o consumo alimentar desse herbívoro, parece afetar pouco sua fisiologia. Hyale niger se mostrou mais resiliente tanto ao aumento da temperatura como a acidificação, não apresentando alterações no seu comportamento alimentar e nem no seu metabolismo. Nossos resultados evidenciam que mesmo espécies que co-ocorrem podem apresentar respostas completamente distintas as mudanças do clima, mostrando que generalizações acerca dos efeitos de alterações ambientais a partir de estudos com uma espécie devem ser feitas de forma cautelosa.

Palavras-chave: aquecimento oceânico, redução de pH, comportamento, herbivoria, peracáridos. 